\title{
Small intestinal mucosal abnormalities in relatives of patients with dermatitis herpetiformis
}

\author{
JANET MARKS, DAVID BIRKETT, SAM SHUSTER, AND D. F. ROBERTS \\ From the University Departments of Dermatology and Human Genetics, Newcastle upon Tyne
}

SUMMARY Jejunal biopsy has been carried out in 19 relatives of patients with dermatitis herpetiformis and stereomicroscopic abnormalities have been found in seven. The majority of the relatives in whom these abnormalities were found had no bowel symptoms: one had the rash of dermatitis herpetiformis. All but one of the propositi of the relatives in whom were found small intestinal mucosal abnormalities themselves had the coeliac syndrome. It is concluded that a genetic factor is involved in the production of the enteropathy of dermatitis herpetiformis as in other forms of the coeliac syndrome.

Two-thirds of patients with dermatitis herpetiformis have a flat or convoluted mucosa in the upper part of the small intestine (Marks, Shuster, and Watson, 1966; Fraser, Murray, and Alexander, 1967; Fry, Keir, McMinn, Cowan, and Hoffbrand, 1967; Marks, Whittle, Beard, Robertson, and Gold, 1968). Its appearance is identical with that seen in gluten-induced enteropathy and we have further emphasized the similarity of the two conditions by demonstrating in dermatitis herpetiformis that the small bowel involvement is maximal proximally and that the instillation of gluten into a normal part of the bowel produces an acute inflammatory response (Shuster, Watson, and Marks, 1968). With one exception (Brow, Parker, and Rubin, 1968) all groups of workers have shown that in the majority of cases the enteropathy responds to gluten withdrawal (Shuster et al, 1968; Fry, McMinn, Cowan, and Hoffbrand, 1968; Marks, 1968). Another feature of gluten-sensitive enteropathy is its familial occurrence demonstrated both preceding the introduction of jejunal biopsy and subsequently (Carter, Sheldon, and Walker, 1959; MacDonald, Dobbins, and Rubin, 1965; Stewart, Pollock, Hoffbrand, Mollin, and Booth, 1967; McCrae, 1969) and we therefore set out to study the families of patients with dermatitis herpetiformis. Received for publication 23 October 1969.

\section{Materials and Methods}

The propositi were 29 patients with dermatitis herpetiformis. The diagnosis was based on the clinical and histological appearance of the rash and on the response of the rash to treatment with dapsone. There was no selection on the basis of intestinal symptoms but routine investigations for the coeliac syndrome had been done (Marks et al, 1966; Shuster et al, 1968; Shuster and Marks, 1970). Nine propositi had been found to have a flat upper small intestinal mucosa, 10 a predominantly convoluted mucosa, and eight a predominance of leaf or finger-shaped villi. In two children the appearance of the jejunal mucosa was not known; the faecal fat excretion was normal though this does not of course exclude the coeliac syndrome. All patients were questioned about their family, and 86 first-degree relatives and one second-degree relative were interviewed. All were asked about diarrhoea, abnormal stools, constipation, weight loss, rickets, and anaemia. Eighteen of the relatives (10 male and eight female) consented to have a small intestinal mucosal biopsy and two of these were later admitted to hospital for further investigations. The relatives in whom these tests were done were selected purely on the basis of their willingness to take part in the investigation. 


\begin{tabular}{|c|c|c|c|c|c|}
\hline \multirow[t]{2}{*}{ Patient } & \multirow[t]{2}{*}{$\operatorname{Sex}$} & \multirow{2}{*}{$\begin{array}{l}\text { Predominant } \\
\text { Stereomicroscopic } \\
\text { Appearance }\end{array}$} & \multicolumn{3}{|l|}{ Relatives } \\
\hline & & & $\begin{array}{l}\text { Relationship } \\
\text { to Patient }\end{array}$ & Clinical State & $\begin{array}{l}\text { Predominant } \\
\text { Stereomicroscopic } \\
\text { Appearance }\end{array}$ \\
\hline J.A. & $\mathbf{M}$ & Flat & Brother $^{1}$ & Rash of dermatitis herpetiformis, otherwise fit & Flat \\
\hline C.L. & $\mathbf{M}$ & Flat & $\begin{array}{l}\text { Son }{ }^{1} \\
\text { Daughter } \\
\text { Daughter }\end{array}$ & $\begin{array}{l}\text { Fit } \\
\text { Fit } \\
\text { Fit }\end{array}$ & $\begin{array}{l}\text { Convoluted } \\
\text { Joined leaves } \\
\text { Joined leaves }\end{array}$ \\
\hline G.B. & $\mathbf{M}$ & Flat & Uncle & Eczema, otherwise fit & Fingers \\
\hline R.W. & $\mathbf{M}$ & Convoluted & Son & Childhood coeliac disease & Not known \\
\hline A.W. & $\mathbf{M}$ & Convoluted & $\begin{array}{l}\text { Brother } \\
\text { Brother } \\
\text { Brother } \\
\text { Son } \\
\text { Daughter }\end{array}$ & $\begin{array}{l}\text { Fit } \\
\text { Fit } \\
\text { Fit } \\
\text { Fit } \\
\text { Fit }\end{array}$ & $\begin{array}{l}\text { Convoluted } \\
\text { Convoluted } \\
\text { Convoluted } \\
\text { Convoluted } \\
\text { Narrow leaves }\end{array}$ \\
\hline W.W. & $\mathbf{M}$ & Convoluted & Brother & Fit & Broad leaves \\
\hline F.B. & $\mathbf{M}$ & Broad leaves & $\begin{array}{l}\text { Sister } \\
\text { Brother }\end{array}$ & $\begin{array}{l}\text { Pernicious anaemia } \\
\text { Fit }\end{array}$ & $\begin{array}{l}\text { Convoluted } \\
\text { Narrow leaves }\end{array}$ \\
\hline G.D. & $\mathrm{F}$ & Broad leaves & Mother & Fit & Joined leaves \\
\hline G.G. & $\mathbf{M}$ & Narrow leaves & Brother & Diarrhoea & Broad leaves \\
\hline R.W. & $\mathbf{M}$ & Fingers & $\begin{array}{l}\text { Sister } \\
\text { Sister }\end{array}$ & $\begin{array}{l}\text { Anaemia, chronic renal disease } \\
\text { Fit }\end{array}$ & $\begin{array}{l}\text { Fingers } \\
\text { Narrow leaves }\end{array}$ \\
\hline L.C. & $\mathbf{F}$ & Not known & Sister & Fit & Broad leaves \\
\hline
\end{tabular}

Table Clinical history and predominant stereo-microscopic appearance of the upper small intestinal mucosa in relatives of patients with dermatitis herpetiformis

${ }^{1}$ Admitted to hospital for further investigation.

In view of the difference in the incidence of a convoluted mucosa in apparently normal people from different parts of the world (Baker, Ignatius, Mathan, Vaish, and Chacko, 1962; Banwell, Hutt, and Tunnicliffe, 1964; England and O'Brien, 1966; Parkins, Eidelman, Perrin, and Rubin, 1966; Burhol and Myren, 1968) and indeed from different parts of Great Britain (Scott, Williams, and Clark, 1964; Salem and Truelove, 1965; Girdwood, Williams, McManus, Dellipiani, Delamore, and Kershaw, 1966; Marks and Shuster, 1970) the stereomicroscopic appearances in the relatives of the patients with dermatitis herpetiformis were compared with those in a control population from Newcastle upon Tyne (Marks and Shuster, 1970). This consisted of a series of coroner's necropsies on 48 people who died suddenly and in whom the incidence of a predominantly convoluted mucosa proved to be $8 \%(4 / 48)$.

SMALL INTESTINAL MUCOSAL BIOPSY

This was done with a Crosby capsule (Crosby and Kugler, 1957) and was taken from the third or fourth part of the duodenum or the first $20 \mathrm{~cm}$ of the jejunum. The specimen was dealt with as previously described (Marks and Shuster, 1970) and the stereomicroscopic appearances were classified according to the predominant feature (Stewart et al, 1967). The terms used in the description of stereomicroscopic appearances of small intestinal mucosa are defined as follows. 'Fingers' are long and narrow and the ratio of width to thickness does not exceed 2:1. 'Narrow leaves' are long and narrow and their width is two to five times that of a finger. 'Broad leaves' may be straight or curled. Their length is often less than that of narrow leaves or fingers. Their width is five to ten times that of a finger. Narrow or broad leaves may be joined but we confine the term 'joined leaves' to the fusion of broad leaves. Joined leaves sometimes form straight ridges and sometimes curve. Their length is usually less than that of leaves or fingers. An angulated mucosal ridge in which there are at least two angles of $90^{\circ}$ or less is a 'convolution'. The depth of a convolution is usually considerably less than the length of a leaf or finger. When no villi or convolutions are present then the mucosa is said to be 'flat'.

\section{Results}

FAMILY HISTORY OF COELIAC DISEASE From the questions we asked our patients about 


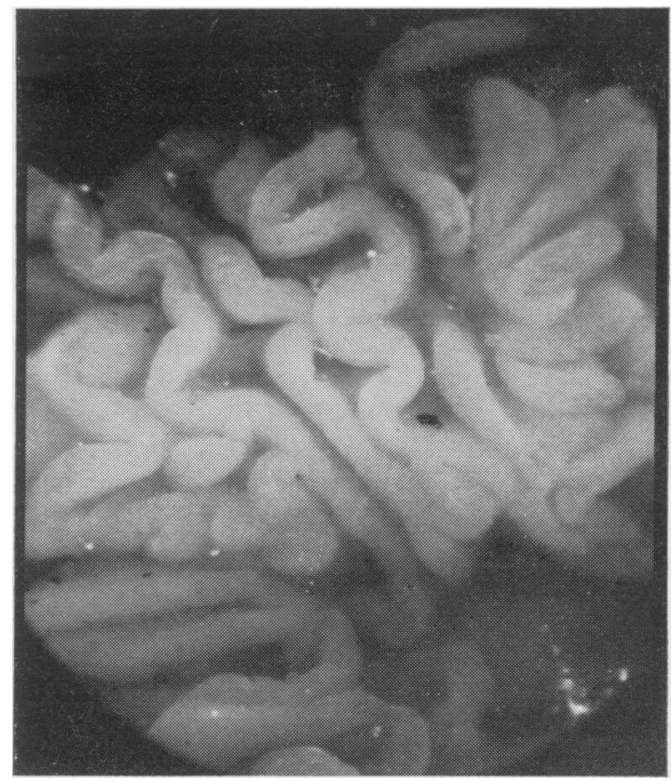

Fig. 1 Stereomicroscopic appearance $(\times 30)$ of the upper small-intestinal mucosa from the brother of a patient (A.W.) with dermatitis herpetiformis and the coeliac syndrome.

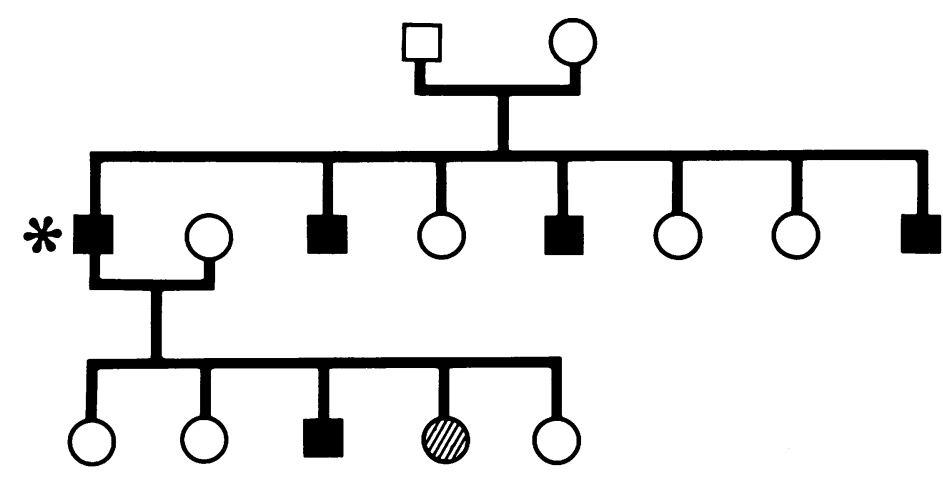

Fig. 2 Family tree of patient A.W. (Squares indicate males, circles females, 1 a male with convoluted mucosa, $\square$ or a relation where the jejunal mucosa was not examined, $\mathbb{\Delta}$ a female with normal jejunal mucosa, and * is the patient with dermatitis herpetiformis.)

their families and from the 87 relatives whom we interviewed personally we obtained a history of childhood coeliac disease in one, of diarrhoea in one, and of anaemia in two first-degree relatives. In one case the anaemia was megaloblastic but from the hospital records it was found to be true pernicious anaemia with achlorhydria and autoantibodies to parietal cells. In the other case the anaemia was found from the records to be due to chronic renal disease and a small intestinal biopsy later showed that it was in any case not associated with a coeliac syndrome (Table). Similarly the patient with diarrhoea later proved to have a normal small bowel mucosa (Table). The patient who had had coeliac disease as a child was the 16-year-old son of a patient with dermatitis herpetiformis who himself had a convoluted mucosa (Table). The boy had presented to a paediatrician when he was 18 months old because of pale, bulky, offensive stools, failure to gain weight, wasting of the buttocks, and hypotonia. He was found to have steatorrhoea though the exact amount of fat excreted was not recorded and no small intestinal biopsy was done. Nevertheless from the dramatic response to a gluten-free diet and continued good health as long as he took the diet there was never any doubt about the diagnosis of coeliac disease.

In none of the other relatives was there a medical history considered to be relevant to the coeliac syndrome but we are well aware that the diagnosis is not excluded by the absence of symptoms. Indeed, in the coeliac syndrome of dermatitis herpetiformis symptoms are not common (Marks et al, 1966; Shuster et al, 1968) and the mucosal abnormalities we later found in the families were nearly all in apparently fit individuals. It is of interest that in the course of the family interviews the brother of one propositus was found to have dermatitis herpetiformis (see Table) and a study of the familial incidence of the rash as distinct from the enteropathy has been done and will be reported separately.

APPEARANCES OF UPPER SMALL INTESTINAL MUCOSA

These appearances are summarized in the Table. One relative had a completely flat mucosa, six had a predominantly convoluted mucosa (Fig. 1), and the remaining 11 had a mucosal pattern which consisted predominantly of leaf or fingershaped villi. Four of the affected relatives were in one family. The members of this family lived apart from one another in widely differing circumstances which made it unlikely that an unusual recent environmental factor alone explained the findings.

The occurrence of a predominantly convoluted mucosa in $32 \%(7 / 18)$ of the relatives of the patients with dermatitis herpetiformis is significantly greater than the incidence of $8 \%(4 / 48)$ in our local control population $(P=0.0065$, calculated by Fisher's exact method). Although numbers are too small for conclusions to be drawn, it is interesting, in view of the usual preponderance of females in coeliac series, that six of our seven patients with a flat or convoluted mucosa were men, although the numbers of men and women examined were almost equal (10 male 
to eight female). This difference is particularly interesting when one considers the high male/ female ratio in individuals with the rash of dermatitis herpetiformis both in this series and in others (Smith, 1966). Most of the abnormalities were found in relatives of the 19 patients who themselves had the enteropathy but one patient with a normal small-bowel mucosa had a sister with a convoluted pattern. Again these numbers are too small for conclusions to be drawn from this. The family tree of one patient is shown in Figure 2.

DETAILS OF TWO RELATIVES ADMITTED TO HOSPITAL FOR FURTHER INVESTIGATION

Brother of J.A.

This was a man of 52 years. He had typical psoriasis but in addition had had a second rash for 26 years. It consisted of extremely itchy papules and blisters on the extensor aspects of the elbows and knees and histological examination of a blister showed it to be typical dermatitis herpetiformis. He had no symptoms to suggest malabsorption but had a completely flat jejunal mucosa and was excreting $10.2 \mathrm{~g}$ fat (normal $<5.0 \mathrm{~g}$ ) in his stools each day.

Son of C.L.

This was a boy of 12 years. He had no skin trouble and no symptoms to suggest malabsorption but was found to have a convoluted mucosa and a faecal fat excretion of $7 \cdot 5 \mathrm{~g} /$ day.

\section{Discussion}

Our finding of abnormalities on jejunal biopsy in seven of the 18 relatives of our patients with dermatitis herpetiformis is of considerable significance. These abnormalities cannot be explained on the basis of the high incidence of a convoluted mucosa in our local population (Marks and Shuster, 1970) for the incidence in the relatives of patients with dermatitis herpetiformis is far greater than in our control group. A special recent environmental factor acting within the families is unlikely to explain this increased familial incidence of small intestinal abnormalities as members of at least one of the families concerned had lived apart for some years. There must therefore be a genetic basis for our findings but we do not know whether the increased incidence of a convoluted mucosa in the families examined is genetically related to the rash or to the coeliac syndrome in the propositus. One way of deciding this would be to determine the incidence of small intestinal abnormalities in the families of patients with dermatitis herpetiformis who themselves have a normal bowel. So far we have studied only seven relatives and one was found to have a convoluted mucosa, but these numbers are too small for definite conclusions to be drawn. Certainly our findings in dermatitis herpetiformis resemble those in the coeliac syndrome where the familial occurrence of the $\Rightarrow$ enteropathy (Carter et $\mathrm{al}, 1959)$ and the presence $\stackrel{+}{+}$ of jejunal biopsy abnormalities in symptomless relatives are well known (MacDonald et al, $\frac{\bar{c}}{\bar{N}}$ 1965; Stewart et al, 1967). Rubin and his group $\frac{\infty}{\sigma}$

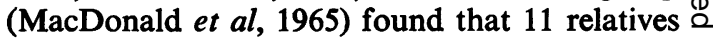
of six propositi had 'severe' mucosal changes and \& a number of other relatives had a 'non-specific' $\vec{\circ}$ abnormality presumably equivalent to our convoluted mucosa. Our results cannot be com- $\vec{\omega}$ pared with those of Rubin's group directly as his $\stackrel{\rho}{\varrho}$ classification was based on light-microscopy $\subsetneq$ appearances and stereomicroscopy was not done. $\vec{\overrightarrow{ }}$

The relationship of the rash of dermatitis herpetiformis to the enteropathy found in two- $\vec{c}$ thirds of the patients is an indirect one, for while $\omega$ the enteropathy usually responds to gluten with- $\frac{\circ}{\square}$ drawal the rash does not (Shuster et al, 1968; $\vec{c}$ Shuster and Marks, 1970) and while the rash can $\subseteq$ always be controlled by dapsone the enteropathy $\overparen{D}$ is unaffected by this drug (Marks et al, 1966; $\vec{\oplus}$ Fraser et al, 1967; Shuster et al, 1968; Shuster and Marks, 1970). A genetic factor is well established in the coeliac syndrome. Our work has shown the common association of dermatitis herpetiformis with this syndrome and so there must be a genetic component in the production $\stackrel{\nabla}{\varnothing}$ of the dermatosis. The mode of inheritance of dermatitis herpetiformis, the proportion of people with it who have the coeliac constitution, and the nature of the factor which precipitates the rash remain to be seen.

The work was financed by grants 17901 and 17903 from the Medical Research Council for which we are grateful. We also wish to acknowledge help from the dermatologists of the Newcastle upon Tyne hospitals and North East Region who referred patients, and from Dr A. J. Watson, Professor A. L. Latner, and Mr Ian Cartwright.

References

Baker, S. J., Ignatius, M., Mathan, V. I., Vaish, S. K., and Chacko, C. C. (1962). Intestinal biopsy in tropical sprue. In Intestinal Biopsy. (Ciba Foundation Study Group, No. 14), 84-101, G. E. W. Wolstenholme and M. P. Cameron, edited by Churchill, London.

Banwell, J. G., Hutt, M. S. R., and Tunnicliffe, R. (1964). Observations on jejunal biopsy in Ugandan Africans. E. Afr. med. J., 41, 46-54.

Brow, J. R., Parker, F., and Rubin, C. E. (1968). Coeliac sprue and the sprue-like lesion of dermatitis herpetiformisseparate or related entities? Gastroenterology, 54, 1223-9.

Burhol, P. G., and Myren, J. (1968). Jejunal biopsy findings in healthy young men. Scand.J. Gastroent., 3, 346-350.

Carter, C., Sheldon, W., and Walker, C. (1959). The inheritance of coeliac disease. Ann. hum. Genet., 23, 266-278.

Crosby, W. H., and Kugler, H. W. (1957). Intraluminal biopsy of the small-intestine. Amer. J. dig. Dis., 2, 236-241. 
England, N. W. J., and O'Brien, W. (1966). Appearances of the jejunal mucosa in acute tropical sprue in Singapore. Gut, 7, 128-139.

Fraser, N. G., Murray, D., and Alexander, J. O'D. (1967). Structure and function of the small intestine in dermatitis herpetiformis. Brit. J. Derm., 79, 509-518.

Fry, L., Keir, P., McMinn, R. M. H., Cowan, J. D., and Hoffbrand, A. V. (1967). Small-intestinal structure and function and haematological changes in dermatitis herpetiformis. Lancet, 2, 729-733.

Fry, L., McMinn, R. M. H., Cowan, J. D., and Hoffbrand, A. V. (1968). Effect of gluten-free diet on dermatological, intestinal and haematological manifestations of dermatitis herpetiformis. Lancet, 1, 557-561.

Girdwood, R. H., Williams, A. W., McManus, J. P. A., Dellipiani, A. W., Delamore, I. W., and Kershaw, P. W. (1966). Jejunal biopsy in patients with malabsorptive disease. Scot. med. J., 11, 343-355.

MacDonald, W. C., Dobbins, W. O., III, and Rubin, C. E. (1965). Studies of the familial nature of coeliac sprue using biopsy of the small-intestine. New Engl. J. Med., 272, 448-456.

McCrae, W. M. (1969). Inheritance of coeliac disease. J. Med. Genet., 6, 129-131.

Marks, J., and Shuster, S. (1970). Small-intestinal mucosal abnormalities in various skin diseases-fact or fancy? Gut, 11, 281-291.

Marks, J., Shuster, S., and Watson, A. J. (1966). Small-bowel changes in dermatitis herpetiformis. Lancet, 2, 1280-1282.
Marks, R. (1968). Dermatitis herpetiformis and the gastrointestinal tract. Trans. St. John's Hosp. derm. Soc. (Lond.), 54, 141-147.

Marks, R., Whittle, M. W., Beard, R. J., Robertson, W. B., and Gold, S. C. (1968). Small-bowel abnormalities in dermatitis herpetiformis. Brit. med. J., 1, 552-555.

Parkins, R. A., Eidelman, S., Perrin, E. B., and Rubin, C. E. (1966). A preliminary study of factors affecting blood lipid levels in three groups of Yemenite Jews. Amer. J. clin. Nutr., 18, 134-148.

Salem, S. N., and Truelove, S. C. (1965). Small-intestinal and gastric abnormalities in ulcerative colitis. Brit. med. J., 1 , 827-831.

Scott, G. B., Williams, M. J., and Clark, C. G. (1964). Comparison of jejunal mucosa in post-gastrectomy states, idiopathic steatorrhoea, and controls using the dissecting microscope and conventional histological methods. Gut, 5, 553-562.

Shuster, S., and Marks, J. (1970). Systemic Effects of Skin Disease. Heinemann, London. In Press.

Shuster, S., Watson, A. J., and Marks, J. (1968). Coeliac syndrome in dermatitis herpetiformis. Lancet, 1, 1101-1106.

Smith, E. L. (1966). The diagnosis of dermatitis herpetiformis. Trans. St. John's Hosp. derm. Soc. (Lond.), 52, 176-196.

Stewart, J. S., Pollock, D. J., Hoff brand, A. V., Mollin, D. L., and Booth, C. C. (1967). A study of proximal and distal intestinal structure and absorptive function in idiopathic steatorrhoea. Quart. J. Med., 36, 425-444. 